\title{
Quem, afinal, apoiou o Plano Collor?
}

\author{
Who supported the "Plano Collor"?
}

ALEXANDRE F. S. ANDRADA****

\begin{abstract}
RESUMO: No livro Economia Brasileira Contemporânea, Lavínia Barros de Castro afirma que o Plano Collor "recebeu críticas de todas as partes", que o "bloqueio dos recursos foi considerado uma inadmissível intervenção estatal”, e que o congelamento de preços, o ajuste fiscal e o caráter recessivo do plano foram questionados. Aqui, mostramos que essas afirmações são equivocadas. Analisando artigos, colunas e entrevistas publicadas à época, tentamos demonstrar que o plano econômico teve, durante suas primeiras semanas de vigência, amplo apoio de empresários, políticos, economistas e até mesmo da população do país.

PALAVRAS-CHAVE: Plano Collor; história do pensamento econômico brasileiro.
\end{abstract}

ABSTRACT: In the book Economia Brasileira Contemporânea (Brazilian Contemporary Economy) Lavinia Barros de Castro states that the Collor Plan "received criticism from all sides", the "the monetary assets blocked was considered an unacceptable state intervention" and that the freezing of prices, the fiscal adjustment and the recessive character of the Plan were also questioned. We argue that these claims are misleading. Analyzing articles, columns and interviews published at that time, we argue that the economic plan received, during its first weeks, a wide support from businesspeople, politicians, economists and even the general population.

KEYWORDS: Collor Plan; history of brazilian economic thought.

JEL Classification: B; B2; N; N1; N16.

\section{INTRODUÇÃO}

No livro Economia Brasileira Contemporânea, 1945-2010, Lavínia Barros de Castro afirma:

"O Plano Collor recebeu críticas de todas as partes. O bloqueio dos recursos foi considerado uma inadmissível intervenção estatal, que tirava a

\footnotetext{
* Professor Adjunto do Departamento de Economia da Universidade de Brasília (UnB). Brasília/DF, Brasil. E-mail: afsa@unb.br. Submetido: 28/Janeiro/2016; Aprovado: 31/Janeiro/18.

** O autor agradece a Gustavo Barros, ao editor deste periódico, o sr. Luiz Carlos Bresser-Pereira, e aos pareceristas anônimos, por seus comentários enriquecedores.
} 
confiança dos poupadores no sistema financeiro nacional, com graves consequências para o país. Argumentava-se, ainda, que o limite imposto era tão baixo, que prejudicava até os pequenos poupadores. Outros aspectos do plano também questionados foram: o congelamento de preços; o ajuste fiscal, que se baseava no aumento de receitas e não em cortes de gastos; e o caráter fortemente recessivo do plano. (Castro, 2013, p. 139)

Este artigo busca mostrar que essas afirmações são incorretas e/ou precisam ser mais bem qualificadas. Lavínia sugere uma recepção hegemonicamente negativa ao Plano Collor, isso, porém, não corresponde aos fatos. Além de apoio popular, medido por diferentes institutos de pesquisa, o Plano contou com o apoio e as simpatias de uma significativa quantidade de influentes jornalistas, empresários e economistas. Como forma de demonstrar essa tese, apresentamos um levantamento das opiniões favoráveis ao Plano expressas por importantes economistas brasileiros em artigos, reportagens e entrevistas publicados em três dos principais jornais do país àquela época: O Estado de São Paulo (OESP), Folha de São Paulo (FSP) e Jornal do Brasil (JB). Os dois primeiros - ainda hoje entre os principais jornais do país - publicavam inúmeros artigos de economistas daquele estado, notadamente de suas principais universidades, como a USP, Unicamp e FGV. Aquele último periódico, um dos mais influentes àquela altura, era um importante veículo na divulgação das ideias dos autores fluminenses, como os professores da FGV, PUC e UFRJ, por exemplo.

Nosso levantamento se limita às primeiras semanas de vigência do Plano. Isso por dois motivos. Primeiro porque em pouco mais de três meses de vigência - como constatam Bresser e Nakano (1991) - era evidente que o Plano havia fracassado. Segundo, porque nosso objetivo é capturar a percepção imediata em relação às medidas de março de 1990, algo dificilmente obtenível em artigos acadêmicos publicados em periódicos.

A partir do levantamento deste material, conseguimos demonstrar outros equívocos de Castro (2013). A afirmação da autora que todos ou quase todos os analistas entenderam o bloqueio dos haveres financeiros como "uma inadmissível intervenção estatal" é equivocada. A ideia de um alongamento compulsório da dívida pública interna era um espectro que rondava o debate político e econômico do Brasil já no final dos anos 1980, como já registrado por autores como Carvalho (2000). O volume do bloqueio foi, de fato, visto por quase todos como excessivo. No desenho original, o plano represaria algo como $80 \%$ da liquidez total do país no conceito de M4. Entretanto, para muitos analistas e mesmo de acordo com as sugestões dos formuladores do Plano [v. Modiano in FSP, 1990g], esse excesso não foi acidental. Se fosse para errar - pensaram - que fosse por excesso. Pois caso o bloqueio se mostrasse frouxo, os riscos de detonação de um processo hiperinflacionário eram enormes. Ao passo que se o bloqueio se mostrasse excessivo, o governo poderia injetar liquidez na economia de uma forma ordeira, dado que retomara o controle da oferta monetária. Com um bloqueio de liquidez dessa magnitude, a reação da maioria dos analistas em relação ao congelamento de pre- 
ços foi, em geral, de desprezo. Dada a escassez de moeda, essa era uma medida vista como insignificante e até mesmo desnecessária [v. Bacha, 1990b].

$\mathrm{O}$ ajuste fiscal foi recebido com simpatia por várias analistas. Em contraste com o período do Cruzado, havia se formado um virtual consenso em torno da tese de que o déficit público da ordem de $8 \%$ do PIB era o motor fundamental do processo inflacionário. O Plano almejava um superávit de $2 \%$, ou seja, um ajuste da ordem de $10 \%$ do PIB em um ano. Previam-se medidas para aumentar a arrecadação e para reduzir os gastos. No primeiro grupo incluíam-se, por exemplo, a cobrança de IOF sobre operações em bolsa, aumento do IPI e a cobrança de IR das atividades agrícolas. No segundo grupo estavam o fim de subsídios, um amplo programa de privatização, extinção de órgãos, autarquias e ministérios etc.

O enxugamento da liquidez promovida pelo Plano certamente causaria uma significativa contração da atividade econômica. Em 1990, o PIB encolheu 4,35\%, pior resultado da série do IBGE. Mas muitos analistas acreditavam ser impossível pôr termo a uma inflação de 1.972,91\% - como registrado pelo IPCA de 1989 sem a ocorrência de um ajuste recessivo.

O Plano Collor não pôde ser reduzido ao sequestro dos ativos financeiros. Ele era formado por um amplo conjunto de medidas, cujas partes agradavam aos setores da esquerda e da direita. Os economistas entusiastas do Plano, por isso mesmo, iam desde velhos liberais da FGV-Rio que haviam servido ao regime militar, passando por desenvolvimentistas da Unicamp.

O artigo está dividido em duas seções. Na primeira, apresentamos uma visão geral sobre o contexto no qual o Plano surge, bem como das medidas anunciadas em 16 de março de 1990. Na segunda, apresentamos as visões favoráveis ao Plano (em diferentes gradações) apresentadas por influentes economistas nas páginas daqueles três grandes jornais.

\section{O PLANO COLLOR: O CONTEXTO E AS MEDIDAS}

Em março de 1990, mês em que Fernando Collor assume a Presidência, o Brasil registrou a maior taxa de inflação de sua história. Medida pelo IPCA ela foi de $82,39 \%$. Vivíamos ali o ponto alto de uma espiral inflacionária cujas causas remontam a uma série de decisões domésticas e eventos externos que se desenrolavam há pelo menos uma década [v. Bresser-Pereira, 1996].

Durante o governo de José Sarney (1985-1990) o Brasil conhecera três diferentes padrões monetários, quatro ministros da Fazenda e três grandes pacotes de combate à inflação. Ainda que alguns progressos tenham sido obtidos, a estrutura institucional do país foi fortemente abalada nesse processo. Cada um desses planos implicou congelamento de preços, mudanças e expurgos nos índices oficiais de inflação, na política de reajuste de salários, dos indexadores. Se a alta inflação já é um forte ruído para o planejamento de longo prazo, a incerteza jurídica observada no país ajudava a piorar o cenário.

Em 1989, esse clima de incerteza parecia chegar ao limite. O governo Sarney já era àquela altura um cadáver insepulto. As atenções se voltavam para as primei- 
ras eleições diretas para Presidente desde 1960. Era preciso saber quem seria e o que faria o novo Presidente. As primeiras pesquisas de intenção de voto, divulgadas no início de 1989, mostravam Leonel Brizola (PDT) na liderança, seguido por Lula da Silva (PT). Ambos candidatos de esquerda, cujos discursos soavam como pesadelo para os mercados. Temia-se que a vitória de um deles - especialmente Lula - implicasse a ruptura com a ordem jurídica então vigente. A partir de abril, Fernando Collor (PRN) assume a liderança nas pesquisas. Collor apresentava-se com um discurso econômico mais liberal, sendo visto com mais simpatias pelo mercado. Mas isso não fora suficiente para acabar com as intranquilidades. Mesmo com sua vitória no segundo turno, em dezembro de 1989, a inflação continuou a acelerar. $\mathrm{O}$ medo da esquerda fora substituído pela incerteza em relação às medidas a serem adotadas pelo presidente eleito. Era evidente, pelo cenário em acelerada degradação, que o novo governo não teria tempo e espaço para medidas gradualistas. Esperava-se um pacote para o primeiro dia de seu mandato.

Não é tarefa trivial definir quando o processo inflacionário se transmuta em hiperinflação. A referência mais comum (e arbitrária) utilizada na literatura para o início da hiperinflação é quando o aumento de preços supera a marca dos $50 \%$ ao mês [v. Cagan, 1956]. Usando o IPCA como medida, o Brasil esteve, portanto, em uma situação hiperinflacionária entre dezembro de 1989 e março de 1990, segundo este critério.

Se em março de 1990 a inflação foi quase o dobro do ponto de corte sugerido por Cagan (1956), por que a economia brasileira não conheceu a hiperinflação em seu grau mais severo, isto é, quando o público repudia completamente a moeda nacional? A resposta é que enquanto o cruzado era continuamente desprezado pelo público, o governo era capaz de ofertar uma outra "moeda", que protegia seus detentores da corrosão inflacionária. À época eram comuns as referências à existência de duas moedas no Brasil. A "moeda dos pobres" (o cruzado) e a "moeda dos ricos" (os títulos públicos que pagavam juros e tinham liquidez diária). O overnight - e os fundos a ele atrelados - era o fator institucional que permitiu que o país convivesse com inflações altas sem ter conhecido a hiperinflação. O dinheiro aplicado no overnight era uma massa na qual se confundiam a poupança financeira, com a moeda demandada para transações, precaução e especulação.

Com a interrupção do fluxo voluntário de financiamento externo a partir de 1982, o governo brasileiro passou a recorrer ao endividamento doméstico e ao imposto inflacionário para cobrir seus déficits. Com a inflação crescente e com a redução drástica na demanda por moeda, o imposto inflacionário se tornava cada vez menos significativo [v. Dall'Acqua, 1989]. Foi preciso, então, apelar ainda mais fortemente ao endividamento doméstico. Mas quanto maior a dívida, a inflação e a incerteza, maiores juros e menores prazos de rolagem são exigidos pelo público. $\mathrm{O}$ overnight representava, portanto, o descontrole das contas públicas, a captura pelo governo da maior parte da poupança do país, como também a oferta de um ativo financeiro capaz de substituir os cruzados.

Mas, se por um lado o overnight postergava a ocorrência do caos, de outro ele era um obstáculo fundamental para a redução da inflação. Imagine que o governo optasse por um novo congelamento de preços. Nesse caso, parte significativa dessa 
massa de recursos mantidos sob a forma de títulos públicos transformava-se imediatamente em moeda, permitindo que os agentes consumissem e especulassem com bens que estivessem defasados. Essa pressão de demanda provocaria desabastecimento, ágio e inflação. O governo poderia optar por uma medida mais tradicional: elevar a taxa de juros de forma a estimular os agentes a manterem seus recursos sob a forma de títulos, evitando as pressões de demanda. Ocorre que essa elevação dos juros teria que ser significativa e implicaria um aumento insustentável do custo fiscal para a rolagem da dívida. O corte de gastos exigido para equilibrar o orçamento do governo - na ordem de $8 \%$ à época do Plano Collor - era inviável politicamente e tornado ainda mais difícil após a promulgação da Constituição de 1988. Neste cenário, o governo seria levado mais cedo ou mais tarde a imprimir moeda para fazer frente aos seus compromissos, reforçando a pressão inflacionária. E ainda que o governo pudesse arcar com esse custo de um modo não inflacionário, era possível que o efeito riqueza percebido pelos detentores de títulos superasse o efeito substituição, de forma que o aumento dos juros provocaria uma pressão de demanda na economia.

Esse dilema da política econômica foi se tornando cada vez mais claro. O bloqueio da liquidez, que Lavínia (2013) afirma ter sido "considerado inadmissível” e que Leitão (2013) classifica como "loucura", será, na verdade, entendido por muitos analistas como uma medida inevitável para afastar a hiperinflação. Esse tema foi muito bem explorado por Carvalho (2000). Trata-se de um equívoco achar essa medida foi apenas uma insanidade derivada do comportamento imprevisível de Collor, ou de um devaneio de uma equipe econômica inexperiente. O bloqueio respondia às preocupações com a rápida remonetização da economia quando da desinflação abrupta, da retomada do controle da política monetária e do peso fiscal da rolagem da dívida pública. Não por acaso, a ideia de um alongamento unilateral da dívida pública já rondava o debate econômico brasileiro e, a partir da proximidade das eleições, os boatos sobre sua ocorrência se tornam cada vez mais comuns.

Em artigo sugestivamente intitulado "Moratória interna, dívida pública e juros reais", Marques e Verlang (1989, p. 19), por exemplo, registraram que "em diversas ocasiões, no passado recente, circularam rumores que o governo poderia deixar de honrar os serviços de sua dívida interna”. Em outro trabalho, também anterior ao Plano, os autores voltam ao tema, dizendo que a "moratória da dívida pública interna, ou o alongamento compulsório dos prazos de vencimentos dos títulos, tem sido tema recorrente no debate econômico nacional". E que "recentemente, este assunto tornou-se de especial interesse", por conta da "proximidade da mudança de comando presidencial” (Idem, 1990, pp. 191-2).

Álvaro Antônio Zini Jr., então professor da FEA-USP, destacava-se com um dos principais defensores do alongamento compulsório da dívida pública, seja em textos acadêmicos, seja em artigos publicados na imprensa [v. Zini, 1989a, 1989b, 1990 e Giambiagi e Zini, 1993]. Sua opinião era a de que "o governo deveria converter compulsoriamente toda a dívida mobiliária em títulos de 10 anos" que pagassem juros de $10 \%$ a.a. e que "o início da amortização" deveria se dar "a partir do oitavo ano". Seu diagnóstico era de que a "dívida mobiliária federal é de títulos de curto prazo (60 dias em média)", sendo "extremamente líquida", pois havia 
"garantia implícita de recompra" [v. Carvalho, 1993]. Rolava-se, em média, "US\$ 30 bilhões diariamente no overnight", enquanto a base monetária seria de algo como "US\$ 5 bilhões ou 1,5\% do PIB". Para o autor, esse era o "mecanismo de propagação inflacionária", o qual deixava "aberta a possibilidade de fuga para ativos reais e inviabilizava os programas de estabilização", dado que tornava "o financiamento cronicamente inviável" (Zini, 1989a, p. B2).

O deputado federal César Maia (PDT-RJ), então principal economista do PDT e nome certo para a Fazenda no caso de vitória de Brizola, escreveu em abril de 1989 um texto intitulado "Um acordo para a dívida interna". Segundo Maia, crescia "o clima de desconfiança em relação ao day after eleitoral". Um dos sinais dessa desconfiança seria uma pesquisa que mostrava uma "alta porcentagem de aplicadores disposta a retirar seu capital do financiamento da dívida pública". Segundo o autor, chegara-se a um ponto em que "a grande questão" seria a de "como alongar o perfil da dívida mobiliária federal?". O deputado propunha uma saída negociada com os credores (Maia, 1989a).

No dia 14 de janeiro de 1990 o jornal FSP noticiava que Rudiger Dornbusch, então professor do MIT, afirmara "que a dívida pública" brasileira precisaria "ser compulsoriamente consolidada em títulos de longo prazo negociável, com juros de $3 \%$ ao ano". E que o plano econômico de Collor falharia se não se tomassem "medidas logo no início do governo para suspender por alguns meses o direito dos aplicadores de fazerem resgates no overnight”. Segundo Dornbusch, “a liquidez do overnight” era incompatível com um programa de estabilização". Destacava ainda que "para o governo" conseguir segurar "os aplicadores no overnight em bases voluntárias", seria necessário "oferecer taxas de juros excessivamente elevadas", que "inviabilizariam o êxito da estabilização", já que "os contribuintes não aguentariam a carga fiscal necessária para o governo pagar esses juros" simultaneamente com a manutenção de um “conjunto das contas públicas em superávit" (Dornbusch, 1990).

Para muitos [v. Carvalho, 2006], o texto que mais se aproxima de uma justificativa teórica do Plano Collor é "Crise e Reforma Monetária no Brasil”, de Luiz Gonzaga Belluzzo e Júlio Jorge de Almeida. Os autores identificam a moeda indexada - que em "sua forma mais desenvolvida" correspondia "aos passivos bancários de emissão por um dia que rendem a taxa overnight e cujo principal lastro" era a LFT - com a perda de controle da política monetária. E como forma de "afastar o fantasma da hiperinflação", os autores se colocam do lado daqueles "que não veem outra saída senão o 'calote' da dívida interna”. Como precedentes históricos dessa medida radical citados são o da Alemanha após a II GM e o da Argentina de 1989. A proposta para o Brasil apresentada por Belluzzo e Almeida envolvia a "criação de uma nova moeda e a suspensão condicionada da liquidez na moeda antiga" (Belluzzo \& Almeida, 1990, pp. 67-73).

Carvalho (2006) - então parte da equipe econômica do candidato do PT - afirma que a proposta de reforma monetária do Plano Collor fora originalmente desenvolvida por economistas do PMDB. Diante da inviabilidade da candidatura de Ulysses, ele fora levado para o PT, onde teria sido bem recebido por parte da equipe. As reações públicas de Aloízio Mercadante, quando do lançamento do Plano - como veremos adiante - dão robustez a essa tese. Carvalho (2006) acredita que o Plano só 
chegara ao comitê de Collor após o segundo turno das eleições, levado por Kandir - também professor da Unicamp e que apoiara o candidato do PT - e que se tornaria ministro de Collor. Essa última ilação, porém, é incorreta. O próprio Collor, em entrevista datada de 2010, afirma que a ideia do confisco já rondava sua equipe antes mesmo do segundo turno das eleições [v. Brígido e Alvarez, 2010].

O Plano Collor começa antes mesmo da posse do novo presidente. No dia 2 de março, Collor teve um encontro público com o presidente Sarney no Palácio do Planalto. Em conversa privada, foram acordadas algumas medidas de preparação para as mudanças econômicas por vir. No dia 13, o BCB desvalorizou o câmbio em $10,72 \%$, e na quarta-feira, dia 14 , véspera da posse, foi decretado um feriado bancário, que valeria até o dia 16 . Esse processo coordenado entre as equipes econômicas deu ainda mais aspecto de surpresa às medidas, já que a relação entre Sarney e Collor era pouco amistosa desde 1987. Muitos esperavam um choque - inclusive com decretação de feriado bancário - para o dia 15 ou 16, mas ninguém esperava que isso ocorresse ainda no governo Sarney.

No dia 15, Collor é diplomado Presidente. E no dia 16 de março de 1990, em discurso à nação, apresentou seu plano de "saneamento moral" da economia. Anunciou-se também a meta de déficit público zero já para o ano de 1990, que seria obtido através de cinco medidas. Uma reforma administrativa para "afastar maus funcionários, fechamento de ministérios, autarquias e empresas públicas"; a suspensão de todos os subsídios; a "incorporação da renda agrícola à base de tributação da União". Também haveria uma "redução drástica na perda de receita tributária, pela indexação quase instantânea dos impostos devidos à União e atualização de alíquotas de IPI". E, por fim, o "reajuste de preços públicos defasados". O terceiro bloco de medidas visava modernizar a economia brasileira, partindo - nas palavras de Collor - "do reconhecimento de que a livre iniciativa é a única via para o crescimento sustentado". Entre as propostas estavam o câmbio flutuante, redução das barreiras à importação, estímulo ao ingresso de capital estrangeiro, um "ambicioso processo de desestatização" e criação dos certificados de privatização e leilão de recebíveis atrasados do Governo Federal (Collor, 1990). Havia, por fim, a parte relativa à reforma monetária.

Todas essas medidas - que constituíam o Plano Collor em sua plenitude - foram apresentadas sob a forma de um conjunto de medidas provisórias (MPs). A Tabela 1 apresenta um resumo delas. A mais impactante delas foi certamente a MP 168, que tratava da reforma monetária. O cruzeiro voltava a ser a moeda nacional em substituição ao cruzado novo. A taxa de conversão era de 1:1. Os saldos em conta-corrente e em caderneta de poupança que superassem a marca de Cr\$ 50 mil ficariam indisponíveis durante 18 meses (até setembro de 1991), quando, então, seriam liberados em 12 parcelas. O dinheiro bloqueado renderia juros de $6 \%$ a.a. mais correção monetária. Ao câmbio da época, Cr\$ 50 mil correspondiam a US\$ 1.300 na cotação oficial e US\$ 610 no mercado paralelo (Carvalho, 2003). As demais aplicações financeiras - inclusive o overnight - seriam bloqueadas até o limite de Cz\$25 mil ou 20\% do total (o que fosse maior), e seriam devolvidos na mesma sistemática.

Mas se o problema era o overnight, por que o bloqueio avançou sobre as aplicações em conta-corrente e poupança? A resposta é a racionalidade dos agentes. 
O temor em relação a alterações nas regras do overnight fez com que muitos transferissem parte de sua riqueza para a conta corrente e poupança, instrumentos que se criam intocáveis. Segundo Nakano (1991, p. 136), "no final do mês de fevereiro" ocorrera "uma verdadeira corrida financeira", com os agentes retirando recursos do over e aplicando na poupança. Isso teria chegado "a movimentar, num único dia, US\$ 5 bilhões", e que na véspera do Plano, teria ocorrido "novos saques massivos" do overnight convertidos em aplicações "em depósitos à vista".

A expectativa do Plano era a de bloquear algo como $80 \%$ da liquidez da economia, nível notadamente exagerado. Isso não teria sido um erro de dosagem do governo, mas antes uma estratégia preventiva. Os formuladores criam que era preferível pecar por excesso. Caso se deixasse liquidez em excesso na economia, corria-se o risco de se desencadear o processo hiperinflacionário, de repúdio total à moeda e aos títulos do governo e a busca por ativos reais e dólar. Caso, porém, o bloqueio fosse excessivo - como o foi - o governo poderia irrigar a economia com moeda de maneira ordeira. A imagem utilizada pelo próprio Presidente Collor era o de uma represa, e que o governo abriria as torneiras à medida que a economia demandasse. Aliás, retomar o controle da oferta monetária era o objetivo fundamental da medida (Carvalho, 2006), e logo as chamadas “torneirinhas” começaram a ser abertas.

Tabela 1: Principais Medidas Provisórias do Plano Collor

\begin{tabular}{|c|c|}
\hline $\begin{array}{l}\text { Medida } \\
\text { Provisória }\end{array}$ & Principais medidas \\
\hline 151 & Extinção ou dissolução de Autarquias, Fundações, Empresas Públicas e Sociedades de Economia Mista \\
\hline 153 & Definia os crimes de abuso do poder econômico \\
\hline 154 & $\begin{array}{l}\text { Instituía a "nova sistemática para reajustes de preços e salários", proibindo reajuste de preços sem } \\
\text { prévia do Ministério da Economia }\end{array}$ \\
\hline 155 & Criava o Programa Nacional de Desestatização (PND) \\
\hline 156 & Tratava dos crimes contra a Fazenda Pública, isto é, das medidas de evasão e sonegação de impostos \\
\hline 157 & $\begin{array}{l}\text { Criava os certificados de privatização, que eram títulos de emissão do Tesouro Nacional, os quais } \\
\text { poderiam ser usados para a compra de empresas públicas }\end{array}$ \\
\hline 158 & Tratava da redução de impostos para importação \\
\hline 160 & $\begin{array}{l}\text { Tratava do IOF, o qual passava a incidir sobre títulos de valores mobiliários, operações com ouro, } \\
\text { saques da caderneta de poupança. As alíquotas iam de } 8 \% \text { até } 35 \%\end{array}$ \\
\hline 162 & $\begin{array}{l}\text { Imposição do pagamento de imposto de renda de } 25 \% \text { sobre os ganhos líquidos obtidos em } \\
\text { operações em bolsa de valores, de mercadorias, futuros e "outros mercados organizados" }\end{array}$ \\
\hline 165 & Proibia os títulos ao portador \\
\hline 167 & Alterava as regras do IR sobre as atividades rurais \\
\hline 168 & Instituía o Cruzeiro como a nova moeda nacional \\
\hline 173 & $\begin{array}{l}\text { "Não será concedida medida liminar em mandados de segurança e ações ordinárias e decorrentes } \\
\text { das medidas provisórias } 151,154,158,106,161,162,164,165,167,168 \text { de } 1990 "\end{array}$ \\
\hline
\end{tabular}

Fonte: Presidência da República. Elaboração própria.

Isso, aliás, ajuda a entender a principal crítica feita à parte monetária do Plano, conhecida principalmente por conta do artigo de Pastore (1991). O problema do processo inflacionário, afirmava, não é o estoque de moeda existente, mas sim o fluxo de moeda nova continuamente aportada na economia. Além disso, como garantir que não haveria uma aceleração na velocidade de circulação dos cruzeiros 
emitidos, provocando, mais uma vez, inflação? Os defensores do Plano, por outro lado, afirmavam que sem o bloqueio dos haveres o governo não teria controle nem do estoque, nem do fluxo de moeda.

Ainda que o congelamento da liquidez tenha sido a medida mais drástica e controversa, ela foi apoiada por amplos setores da sociedade. E mais, a Tabela 1 dá a dimensão das mudanças implantadas pelo Plano. Por exemplo, na parte do ajuste fiscal o governo buscava, a fim de reduzir gastos, implementar um amplo processo de privatizações (MPs 155 e 157), extinguir órgãos (MP 151) e acabar com subsídios. Outras medidas adotadas também eram defendidas pelos organismos internacionais, como a abertura do país ao comércio exterior (MP 158) e a adoção do câmbio flutuante (Circular 1.686 do BCB). Todas essas medidas eram bandeiras dos liberais, inclusive os nativos. Já a esquerda podia comemorar o fim da chamada "ciranda financeira", a reestruturação da dívida interna, a taxação sobre ganhos obtidos no mercado financeiro (MP 160), a cobrança de IR das atividades rurais (MP 167). A tese de que o custo do ajuste recairia sobre os $10 \%$ ou $5 \%$ mais ricos do país, em vez da massa de trabalhadores, também tinha apelo para esse grupo.

\section{AS OPINIÕES FAVORÁVEIS AO PLANO COLLOR}

É conhecida a afirmação de Maquiavel de que os homens se esquecem mais facilmente a perda do pai do que a perda do patrimônio. O Plano Collor gerou perdas suficientes para criar uma multidão de órfãos patrimoniais. Mesmo que se cresse que o governo devolveria tudo com juros e correção monetária - o que já era uma aposta -, o proprietário só teria acesso ao total de seus recursos após 30 meses ( 18 de carência e 12 de pagamentos). Com esse clima propício para as revoltas, o que se poderia esperar era um pouco de fúria por parte da população. $\mathrm{O}$ governo, aliás, esperava por isso.

No dia 26 de março, o JB publicou uma reportagem intitulada "Aceitação surpreende economistas". O texto afirma que a expectativa do governo era que houvesse fortes reações às medidas, de modo que até um esquema especial fora montado para garantir a integridade física dos funcionários do Banco do Brasil. Um dos diretores do banco acreditava que "o sujeito" iria "ao banco com um cheque no bolso e uma pedra no outro". Ibrahim Eris, presidente do BCB, também se mostrava aliviado com o clima de tranquilidade: "Afora alguns episódios isolados, não houve grandes tumultos. É incrível. A sociedade demonstrou que a interrupção do processo inflacionário era urgente e, por isso, soube compreender o alcance da nossa proposta" (JB, 1990h).

No dia 18 de março de 1990 a FSP publicou uma pesquisa de opinião do instituto Datafolha sobre o Plano recém-editado. Dos entrevistados, $58 \%$ achavam o plano "bom", e apenas $8 \%$ o julgavam "ruim". Índice significativo. A própria reportagem lembrava que o Plano Cruzado obtivera o apoio de $59 \%$ à época de seu lançamento. No dia 23 de março, $81 \%$ achavam o plano "bom", e apenas $5 \%$ o julgavam "ruim" (FSP, 1990i). O JB de 26 de maio - ou seja, mais de dois meses após o lançamento do Plano - trazia os números de uma pesquisa realizada pelo 
IBOPE, Enquanto o governo Collor era aprovado por $67 \%$ dos entrevistados, o plano econômico, por $74 \%$ dos entrevistados (JB, 19901).

Parte influente da elite econômica do país também demonstrou boa vontade com o plano. Abílio Diniz, dono do Grupo Pão de Açúcar, se mostrava tranquilo: "As medidas são impopulares... são drásticas, porém a gente sabia que eram necessárias" (JB, 1990d). Antônio Ermírio de Moraes, superintendente do Grupo Votorantim, afirmava: "agora vamos ver os empresários que têm compromisso com o Brasil e aqueles que têm compromisso com o próprio bolso", "é hora de sacrifícios para um Brasil melhor para todos. Estou disposto a pagar minha parte e os ricos têm que pagar as suas". Olavo Setúbal, presidente do Grupo Itaúsa, dizia: "Ou matamos a inflação ou não temos futuro. É como um período de guerra, quando algumas pessoas morrem", e "o grande teste do governo Collor será resistir às choradeiras que estão por aí e não ceder em nada. O que sobrou nas contas é o suficiente até o final do mês" (JB, 1990e).

Os grandes partidos também não condenaram o Plano Collor em sua origem. A base de apoio de Collor em março de 1990 era composta pelo PFL, PDS, PTB e PL. O PFL, dono da segunda maior bancada na Câmara, nas palavras de seu líder, o deputado federal Ricardo Fiúza (PE), declarou apoio integral às medidas de Collor (FSP, 1990f). Já no PMDB, partido de maior bancada na Câmara e composto por vários caciques distintos, havia alguma resistência em relação às privatizações, bem como a demanda da elevação do limite de saque da poupança, mas o partido apoiava a "essência" do Plano. O líder do partido da casa, o deputado Ibsen Pinheiro, fora claro ao afirmar que "o PMDB" apoiava "o programa econômico do Governo", pois não se julgava no "direito de alterar seu eixo principal” (OESP, 199e).

Franco Montoro, presidente do PSDB, afirmou que disposição do partido era a de apoiar as medidas. O então senador Fernando Henrique Cardoso declarou que "algumas medidas são extremamente positivas, como o fim do fundo ao portador que representou uma cacetada na malandragem", para FHC "não houve expropriação de recursos; o dinheiro é da pessoa e está no Banco Central" (FSP, 1990h).

José Serra - então deputado federal pelo PSDB e um dos principais economistas do partido - afirmava que o plano representava "o segundo bilhete premiado que o Brasil tem em mãos nos últimos anos". O primeiro teria sido o Cruzado, mas que fora "rasgado antes da cobrança". Para Serra, o Brasil tinha ali uma "outra grande chance, com um plano tecnicamente melhor elaborado" e com a vantagem de surgir em um "contexto de maior vontade política, em face de um país exaurido pelo castigo da superinflação". Serra destaca que "o ponto essencial” do Plano era a "reforma monetária que enxugou o estoque disponível dos ativos financeiros em cerca de cem bilhões de dólares", o governo teria conscientemente optado pela "tática" de "exagerar na dosagem". Essas medias afastavam "a curto prazo, o risco da hiperinflação". Com o controle da moeda novamente nas mãos do BC, este poderia reinjetaria dinheiro na economia de forma ordeira (Serra, 1990).

O caso do PT é um pouco mais complexo. Carvalho (2006) mostra que a ideia de bloqueio dos haveres fora bem recebida por parte da equipe econômica do partido, especialmente por Aloízio Mercadante. No dia 18 de março, foi transmitida pela TV Manchete uma entrevista com a ministra Zélia, a qual contou com as intervenções do petista. Mercadante afirmara - para a surpresa de Zélia, segundo 
a reportagem - de maneira enfática: "faríamos a mesma coisa. A senhora está de parabéns". Além disso, disse: "posso garantir que nossa bancada no Congresso fará tudo para aprovar as medidas". Falando no plural, Mercadante afirmava; "achamos que a política fiscal prevista no programa é adequada e não vamos agora fazer coro com os descontentes, que não aceitam o fim da especulação financeira' (JB, 1990c). O PT rapidamente mudaria de posição. Em poucos dias sairia um Manifesto à Nação dos partidos de esquerda, no qual repudiavam as medidas de Collor. Mas as palavras de Mercadante estão gravadas para a História.

César Maia (PDT), em coluna do dia 20 de março, afirmava que "todos os candidatos progressistas falavam nas eleições de 89 em um alongamento da dívida interna". Medida que através do Plano Collor fora "realizada de forma drástica", porém "necessária". E que as medidas fiscais do Plano incorporavam propostas "apresentadas ao Congresso pelos chamados setores progressistas, a partir de Bresser em dezembro de 1987", mas as quais foram sempre "rejeitadas pela direita" (Maia, 1989b).

No dia 18 de março, Mário Henrique Simonsen - que fora um dos cotados para assumir a Fazenda - concedeu entrevista ao JB, no qual afirmava que o plano era "ousado" e que tocara "num problema fundamental do combate à inflação: a redução da liquidez". Para o ex-ministro o ajuste das contas públicas - "que é muito importante" - seria "conseguido basicamente às custas do IOF", mas também em partes pela "privatização e redução de incentivos fiscais". As políticas de renda - como o congelamento de preços - eram vistas como "tradicionais", "semelhantes às do Cruzado e do Verão, e que não constituem novidade". Para Simonsen o que o governo fizera em relação à liquidez era "equivalente a um empréstimo compulsório", e que "com esta redução da liquidez e com a mecânica que se estabeleceu, o Banco Central passou realmente a adquirir controle sobre a moeda" (Simonsen, 1990a).

Quando questionado sobre as possibilidades de sucesso do plano, respondeu Simonsen: "operacionalmente, se for bem aplicado, tem grandes chances de sucesso" e que "um plano destes pode reduzir a inflação rapidamente a zero". Em sua interpretação, o Plano Collor era "um dos mais ousados que já houve de combate à inflação". O ex-ministro partilhava da visão que o bloqueio de liquidez fora excessivo, mas também entendia essa medida: "O enxugamento da liquidez foi muito maior do que o necessário para combater a inflação. Então, o governo agiu no sentido da prudência; errar por excesso e não por falta”. Segundo Simonsen, era "importante que as pessoas se convençam de que não houve um confisco, mas um alongamento compulsório. Ou seja, um empréstimo compulsório, mas que este empréstimo, no final de 18 meses, vai ser uma boa aplicação financeira" (Simonsen, 1990a). Em relação aos riscos de recessão, dizia: "A verdade é que é muito difícil fazer omelete sem quebrar ovos, isto é, um programa de combate à inflação sem recessão". Em termos gerais, Simonsen (1990b) julgava que o plano era "extremamente engenhoso", "bem concebido" e "altamente consistente". Quando indagado sobre o congelamento de preços, tratava a medida com relativo desprezo. Afinal, o "mais importante não é o congelamento", mas sim "o aperto à liquidez". Pois "quem remarcou" os preços para cima, "simplesmente não vai conseguir vender", e se veria obrigado a "remarcar para baixo".

Em artigo publicado ainda em março no JB, intitulado Alea jacta est, expressão 
em latim que significa algo como "a sorte está lançada", Simonsen apresenta as particularidades da economia brasileira - com a dívida pública sendo rolada diariamente, com alta liquidez e rentabilidade, o que implicava "que o aumento da taxa de juro real alimentava a fogueira criando mais moeda". Dada essas especificidades institucionais, "para combater a inflação brasileira não bastava cortar o déficit público e desatrelar os reajustes salariais da inflação passada”. Para Simonsen era preciso "separar o joio do trigo", isto é, determinar quanto daqueles ativos financeiros - que representavam uma grandeza de 30\% do PIB - era moeda para transação e quanto era poupança. "O presidente Collor resolveu atacar o tigre inflacionário com a única bala que dispunha na agulha. Só que, ao invés de um tiro de bazuca, lançou-lhe uma bomba de nêutrons, sequestrando $80 \%$ dos ativos financeiros. O tigre esfacelou-se e pelo menos nos próximos 18 meses os riscos de inflação são mínimos" (Simonsen, 1990c).

O JB reportava o apoio dado ao Plano por ex-presidentes do BCB. Carlos Langoni, que ocupara o cargo entre 1980 e 1983, "apesar de todas as restrições, [...] achava que não havia alternativa para o governo do que a adoção das fortes medidas de contenção de liquidez. Para ele "não havia muito espaço para gradualismos"” (JB, 1990i). Em outra oportunidade Langoni (1990) afirmara que "a arquitetura do plano" era "aparentemente sólida", combinando "medidas de curto prazo" - como o ajuste fiscal e monetário - e medidas de "restruturação de médio e longo prazo", como a "das políticas de privatização e liberalização do comércio exterior".

Ernane Galvêas, presidente do BCB por duas vezes (1968-1974 e 1979-1980) e ex-ministro da Fazenda (1980/1985), afirmara: "A medida era necessária. A dose foi muito forte, mas não havia alternativa senão a de pedir concordata e decretar moratória por 18 meses" (JB, 1990i). Galvêas também publicou artigos apresentando duas visões sobre o Plano. Fica evidente que em sua interpretação o bloqueio dos haveres era uma necessidade das circunstâncias. Em sua análise o governo recebera "uma herança maldita", e que a inflação havia desorganizado "a administração pública", paralisando "os investimentos públicos e privados" e que ela havia degradado "os costumes". Vivíamos em um cenário no qual "o governo" se endividava "freneticamente para cobrir o déficit orçamentário, a juros insuportáveis", algo que teria se agravado "principalmente depois da Constituição de 1988". O que ocorrera, então, é que chegara "o momento que todos nós temíamos: o governo ficou sem condições de honrar suas dívidas". Com o "sequestro" de ativos, diz Galvêas, o governo pede "concordata" e promete pagar suas dívidas em 30 meses, ao mesmo tempo em que evita uma corrida bancária, que aconteceria se houvesse apenas o pedido de "concordata" sem o congelamento da liquidez (Galvêas, 1990b).

Em texto intitulado "A grande concordata nacional", Galvêas (1990a) afirma que "diante da impossibilidade inarredável de pagar a dívida interna", o governo pedira "concordata", "estendendo o pagamento de suas obrigações pelo prazo de 30 meses, com 18 de carência". Galvêas coloca de maneira cristalina sua interpretação: "não havia alternativa" e que "a concordata era a única saída". Isso pois no dia 15 de março "o país já estava mergulhado na hiperinflação, caminhando para o caos econômico, de consequências sociais imprevisíveis". Esse desfecho, afirma, era previsível, pois "de toda parte" surgiam "os sinais de inadimplência e o merca- 
do financeiro funcionava, desde muitos meses, sob o risco iminente do calote inevitável”. E "muitos economistas" já previam esse desenrolar da história.

João Paulo dos Reis Velloso, ministro do Planejamento entre 1969 e 1979, foi outro economista ligado ao antigo regime a mostrar apoio ao Plano. Dizia "que o Congresso Nacional, com alguns ajustes menores" deveria "aprovar o plano de estabilização". Para ele a razão era simples. Primeiro porque "o programa" teria "alta probabilidade de reduzir a inflação a taxas muito baixas". Além disso, "recuar", àquela altura, era "cortejar o caos" hiperinflacionário "à la Argentina" (Velloso, 1990). Velloso também mostrava compreensão em relação ao bloqueio. Para ele, "o fundamento dessa opção drástica" era o "receio de uma inundação" de liquidez na economia. Pois, havendo "uns US\$ 115 bilhões" em haveres, havia o temor "que essa massa de recursos, quando se tentasse fazer a estabilização, fosse reorientada maciçamente para ativos reais, e principalmente para consumo". Os perigos do Plano seriam dois: (i) saber se a liquidez existente no sistema era suficiente para "financiar gastos correntes e certo nível de investimento das empresas" e (ii) as incertezas para o ano de 1991, "a maior delas é o que vai acontecer às expectativas e aos preços, quando o bloqueio de ativos for gradualmente levantado" (Velloso, 1990).

Fernando de Holanda Barbosa, outro economista ligado à corrente liberal da FGV-RJ, também se mostrava compreensivo com o Plano Collor, o qual - à diferença dos últimos três choques - estava "alicerçado no tripé" de "políticas de rendas, fiscal e monetária". Sobre a política de rendas, a valer "por um período bastante curto, não superior a 90 dias", Barbosa o via como uma "parte essencial de um plano de estabilização numa economia com alguma rigidez no sistema de preços relativos". Porém, "a consistência de longo prazo" do Plano residia "na política fiscal, com a eliminação permanente do déficit público". O próprio "controle da oferta monetária e da inflação", diz Barbosa, era uma "consequência da eliminação do déficit". Para ele, "o Plano Collor" fora "bastante engenhoso e criativo ao devolver ao Banco Central a capacidade de controlar o estoque de moeda no curto prazo", através da "conversão dos ativos financeiros existentes em 16 de março em dois outros ativos: cruzeiro e títulos denominados na moeda antiga". Desta forma, "o Banco Central readquiriu o controle absoluto dos instrumentos de política monetária, pelo menos no curto prazo, com a introdução da taxa de câmbio flutuante" (Barbosa, 1990).

Roberto de Oliveira Campos, então deputado pelo PDS-MT, não foi exatamente um entusiasta do Plano, mas sua análise mostra a complexidade das medidas anunciadas em março. Campos acreditava que "o Plano Brasil Novo" teria "a vantagem de matar dois mitos". O primeiro seria "o mito estruturalista, segundo o qual a inflação resulta da rigidez das estruturas, e não da expansão da moeda". O segundo seria o mito "da cura indolor da inflação". Para Campos, "curar a hiperinflação sem ajuste recessivo" era "um sonho impossível". Outro "aspecto positivo" do Plano era o dato de "o presidente Fernando Collor proclama o combate à inflação como um objetivo condicionante, sendo todos os demais condicionados". Além disso, "o plano" seria "politicamente magistral", pois dava "buquês de rosas com equânime distribuição de espinhos". As rosas para as esquerdas seriam o "viés antiempresarial", além do "bloqueio do capital" aplicado no overnight, a "forte tributação de ativos financeiros, o congelamento policialesco de preços" e a "punição às Bolsas de Valo- 
res". Já os espinhos - para esse mesmo grupo - seriam "a liberalização cambial e comercial, a reforma emagrecedora do Estado e a privatização". E “esses espinhos” eram precisamente "as rosas" do Plano "para os liberais" (Campos, 1990).

Os economistas da PUC-RJ - escola que forneceu quadros importantes para os governos Sarney, Collor e que se tornaria ainda mais influentes nos anos Itamar e FHC - também não foram críticos ferozes do Plano Collor. Edmar Bacha, sua principal liderança, mostrava total compreensão em relação ao bloqueio dos haveres e sua dose excessiva. Para ele, haveria uma "excessiva liquidez na economia", a qual seria "capaz de destruir um plano de parada súbita da inflação". Isso, pois, "anunciado o plano, os agentes econômicos, escaldados pelas experiências anteriores de congelamento, certamente iriam tratar de desfazer-se de uma parte de sua liquidez, comprando mercadorias". Assim, tornava-se necessário "represar boa parte da liquidez pré-existente, para garantir o sucesso da desindexação". Desta forma, tornara-se "necessário represar uma boa parte da liquidez pré-existente", de forma a "garantir o sucesso da desindexação - com o congelamento". "Tomada essa decisão" - prossegue Bacha - "entende-se o porquê da 'overdose' de contração de liquidez". O autor apresenta alguns motivos, destacamos aqui três. "Primeiro porque era impossível estimar quanto se reduziria a liquidez 'desejada' uma vez anunciado o congelamento de preços e da correção monetária”. Em segundo lugar, "porque essa redução" da liquidez, "estaria magnificada pelo caráter compulsório do alongamento da dívida interna”. E, por fim, “porque as pressões políticas e dos lobbies empresariais e sindicais, uma vez anunciado o plano, seriam todas no sentido de liberar os recursos represados" (Bacha, 1990, p. B2).

Bacha, porém, critica a falta de "acabamento" do Plano e a paralisia do sistema financeiro provocada pelo que ele chama de "overkill da liquidez". Logo ficou claro, inclusive para o governo, que "o dinheiro deixado na economia pelo plano demonstrou ser insuficiente para o giro dos negócios”. Apesar dos problemas - inclusive o receio que as torneiras despejassem liquidez em excesso na economia Bacha afirma: "Tanto o temor da depressão quanto o de um breve retorno à hiperinflação parecem exagerados". Apesar das dificuldades, o autor cria que "a gestão da demanda agregada, por via da progressiva remonetização da economia, parece, assim, estar razoavelmente bem encaminhada" (ibidem).

Sobre o congelamento de preços, Bacha afirmava que enquanto "o Plano Cruzado determinou que ninguém poderia aumentar preços e salários", o "Plano Collor decretou que não tem como aumentar preços e salários porque não tem dinheiro para fazer isso" (JB, 1990j).

No final de março, aparece um artigo no JB escrito por Edmar Bacha, Luís Roberto Cunha, Gustavo Franco e Winston Frisch, todos eles professores da PUC-Rio. Apesar das críticas ao Presidente e a partes do Plano, os autores entendem que este último "traz propostas válidas, como a do alongamento da dívida interna, forte ajuste fiscal e reformas estruturais" que visavam à redução da ação direta do Estado na economia. Alertando para as "tendências janistas do novo governo" e os "traços marcadamente populistas", os autores pediam a preservação do "caráter reformista, anticorporativista e de choque de capitalismo do programa". A preocupação dos autores em relação ao bloqueio dos haveres era de que esses não fossem devolvidos - devidamente corrigidos - após 18 meses, mas não à medida 
em si. Os autores apresentam algumas propostas para fortalecer a confiança no sistema financeiro, para minorar os efeitos recessivos do Plano e para a melhora do processo de privatização, ou seja, uma leitura reformista. Para os autores "o plano inclui medidas importantes de interesse nacional que ferem interessem corporativos altamente organizados", destacando a privatização, as "medidas de política industrial contidas nas" MPs 158 e 161 e a "suspensão dos incentivos fiscais". Elogiavam ainda as "medidas modernizadoras", que incluíam a incidência do IR à grande agricultura, ao setor financeiro e a abolição do anonimato fiscal (Bacha, Cunha, Franco e Frisch, 1990).

Eliana Cardoso, em artigo publicado no dia 29 de março, alertava os leitores sobre os riscos da recessão que se avizinhava, além disso, apresentava fortes críticas ao caráter autoritário do Plano e do governo Collor. Apesar disso, porém, afirmava que "o coro dos economistas confirma que o novo Plano Collor é coerente, bem concebido e corajoso", e que trazia "avanços importantes", como o de "estabelecer que todos devem pagar impostos e que o controle da inflação só é possível com a conquista do controle monetário pelo BC; proíbe mordomias, desmobiliza o patrimônio público não produtivo e privatiza tanto empresas estatais quanto privadas ao interromper subsídios e privilégios”. Em sua análise, "o processo de consolidação e alongamento da dívida ... interrompeu a hiperinflação". Nas palavras da autora: "é verdade que o confisco era inevitável”, pois "se não viesse por decreto, viria de forma ainda mais dramática com a hiperinflação" (Cardoso, 1990.)

Alexandre Kafka, então representante do Brasil no Fundo Monetário Internacional, disse que "o FMI está gostando do plano brasileiro. O plano é bom, mesmo porque não há outra alternativa” (JB, 1990b).

Houve também apoio ao Plano entre os economistas de esquerda e/ou heterodoxos. Maria Conceição Tavares, por exemplo, fora enfática: “é o melhor [plano] que já foi feito neste país. O [ex-ministro Dílson] Funaro deve estar muito contente lá no céu, porque esse era o plano que ele queria". Conceição, repetindo expressão usada exaustivamente naqueles dias, dizia que o Plano Collor era "tecnicamente perfeito", além de ser "muito melhor que o nosso [Plano Cruzado]". Ainda que não tivesse apoiado e nem apoiado Collor, dizia: "Não gosto deste presidente, não trabalhei para ele, mas o plano é fabuloso e pode salvar este país" (JB, 1990f).

Outro autor, também crítico da figura do presidente, que defendia o Plano Collor foi Roberto Saturnino Braga, economista e ex-prefeito do Rio de Janeiro e uma das vozes mais importantes da esquerda brasileira à época. O autor elogia o fato de não ter havido vazamento das informações sobre o bloqueio dos ativos, como também o fato de que "pela primeira vez, um plano de combate à inflação foi posto na conta dos $10 \%$ mais ricos do país, os que podiam e deviam pagar". Destaca ainda que um governo de esquerda jamais poderia ter ido tão longe, pois não haveria condições políticas de em uma "só cajadada desvalorizar pelo confisco a dívida interna, acabar com o déficit público que era o gira dessa dívida, estancar a inflação de um só golpe", além de acabar com o anonimato e o caixa dois através do fim dos títulos ao portador, bem como "recompor as finanças do Estado". Em forma de desabafo, diz Saturnino: "convenhamos, [essas] eram as nossas propostas", de forma que "isso nos obriga a apoiar o Plano Collor".

Luiz Gonzaga Belluzzo era próximo de Zélia e colaborou com o Ministério de 
maneira informal, já que à época era secretário do governo de Fleury (SP). Para Belluzzo, "do ponto de vista técnico", o Plano "só faz sentido". Afinal, se todos concordavam que "a raiz da inflação" estava na "expansão monetária descontrolada", então "como" seria "possível negar os méritos de uma tentativa articulada de conter tal descontrole?". Assim, "por mais que possamos não gostar, individualmente, do efeito imediato das medidas, não há como discordar do seu rigor"(Belluzzo, 1990b).

O ex-ministro da Fazenda Luiz Carlos Bresser-Pereira foi outro destacado membro da esquerda brasileira a receber o Plano de maneira majoritariamente positiva. Poucos dias após a divulgação do Plano, Bresser afirmara que "aos poucos vai se formando um grande consenso de que o Plano Collor é coerente, bem concebido, e tem condições de êxito". Além disso, era um "plano corajoso que tem uma lógica baseada no fato de que o ajuste patrimonial tornou-se inevitável quando se verificou que o ajuste fiscal era insuficiente" (Bresser-Pereira, 1990a).

Em outra publicação, o ex-ministro afirmava que "as quatro políticas que" formavam o Plano estavam "na linha certa". "A política de ajustamento fiscal" era tratada como "forte e progressista". Do lado da política tributária - dizia - a eliminação dos títulos ao portador, a "tributação dos rendimentos do capital, imposto sobre as grandes fortunas", a cobrança de "imposto de renda sobre a agricultura e as exportações" e a majoração do IPI e do IOF. E que "no campo das despesas, a opção foi eliminar empresas e departamentos". Bresser inclusive se lamenta, pois afirma ter se demitido do Ministério "exatamente por não ter conseguido do presidente e da sociedade" o suporte para a implementação "de um conjunto de medidas semelhantes a esse". Sobre a política de comércio exterior, Bresser afirma que ela "também" estava "absolutamente correta", com a liberalização do comércio, a redução dos "controles quantitativos e apoiando a proteção no sistema tarifário". A política de câmbio livre é vista como "o único erro claro". A política de rendas também é elogiada, pois um "congelamento por tempo muito limitado" era visto como "necessário". Para Bresser "a controvérsia real" estava na "reforma monetária". A magnitude da retenção de ativos é vista como "um aperto de liquidez muito violento e indiscriminado". Apesar disso, o balanço final era que era preciso "deixar de lado o nervosismo" e a "indignação que sempre ocorrem quando "mexem no nosso bolso" e apoiar o Plano. Apoio, aliás, que é visto como um "dever patriótico", pois o fracasso do Plano provocaria "consequências trágicas para toda a nação" (Bresser-Pereira, 1990b).

Em artigo publicado no início de abril, Bresser mostra alguma preocupação com o futuro do pacote, mas não se furta a afirmar que "o plano" continuava "a ser coerente e corajoso". Dizia ainda que a lógica do Plano - de que era "inevitável a retenção de ativos financeiros" pelo $\mathrm{BCB}$ - estava baseada no fato de que "o ajuste fiscal, que poderia ter evitado essa retenção, possuía uma dimensão" e requeria uma rapidez de implementação que eram "incompatíveis com as limitações políticas e constitucionais” (Bresser-Pereira, 1990b). Num balanço feito após sessenta dias de vigência do Plano, Bresser afirmava que ainda não era "possível fazer uma avaliação clara sobre suas possibilidades de êxito". Mas, ainda assim, considerava-o "coerente e progressista, combinando de maneira equilibrada ortodoxia e heterodoxia" (Bresser-Pereira, 1991).

Luiz Carlos Mendonça de Barros asseverava que "o Brasil” havia brincado 
“com a inflação durante 16 anos". E que "o Plano Collor é um ataque incondicional à inflação". Fazendo uso da metáfora política de Nixon na China, afirmava que "somente uma economista heterodoxa como Zélia seria capaz de comandar a restrição monetária que está no centro do Plano Collor". Era evidente que não havia "dinheiro na economia para acomodar o nível de preços atual sem que uma depressão se" instalasse no país. Em todo caso, era seria a "primeira vez desde 1974" que "a batalha contra a inflação" começara verdadeiramente no país" (Mendonça de Barros, 1990).

\section{CONCLUSÃO}

Neste artigo buscamos demostrar que o Plano contou com apoio de importantes empresários, jornalistas, economistas e intelectuais brasileiros de ponta a ponta do espectro político, contrariando a afirmação de Barros (2013). Optamos pelas citações diretas como uma forma de demonstrar que nossa tese não é derivada de uma interpretação criativa dos textos.

Nosso trabalho, porém, não deve ser entendido nem como uma defesa do Plano Collor, nem como uma crítica ao livro Economia Brasileira Contemporânea, 1945-2010. E é exatamente por ser uma obra de alta qualidade, referência básica para os interessados na história econômica recente do Brasil, que achamos importante apresentar esse pequeno reparo.

Tampouco deve-se tomar as opiniões reproduzidas aqui como definitivas. $\mathrm{O}$ fato de um ou outro autor ter mostrado apoio ao Plano nas primeiras semanas de vigência não significa que suas análises permaneceram inalteradas.

Simonsen (1991, p. 128) já apresenta uma visão menos elogiosa sobre as medidas. Fala em "desmantelamento da confiança no direito de propriedade"; que "no campo salarial" o Plano seria "de uma generosidade comovente, mas pouco compatível com um programa de estabilização"; que "a reforma administrativa é cheia de efeitos pirotécnicos, mas pouco promete em matéria de redução de déficit público"; que o programa de privatização seria feito "enfiando os certificados de privatização pela goela das instituições financeiras"; e que impressionava a "ambiguidade ideológica" do Plano.

Bresser-Pereira e Nakano (1991, pp. 107-10) também logo começaram a externar uma percepção mais pessimista em relação às medidas do plano. Para os autores, "noventa dias após o lançamento [...] a recessão continuava a ser o resultado mais provável, ao mesmo tempo que se tornava claro que a inflação estava de volta". Os autores apresentam, então, três correntes explicativas para a volta da inflação: monetarista, keynesiana e neoestruturalista. A primeira é aquela da tese de Pastore (1991). A segunda cria que a inflação voltara porque a expansão da oferta monetária causara excesso de demanda. Por fim, a neoestruturalista chamava a atenção para o desequilíbrio na estrutura de preços relativos quando do congelamento de preços, e das medidas tomadas pelo governo que agravaram esse fenômeno, ensejando a continuidade do processo inflacionário.

Note-se, porém, que o objetivo deste artigo é apresentar apenas uma fotografia 
das opiniões nas primeiras semanas de vigência do Plano. A construção de uma narrativa sobre o processo que levou ao fracasso das medidas e a mudança nas análises desses economistas - ainda que interessante - está além do escopo do texto.

\section{REFERÊNCIAS BIBLIOGRÁFICAS}

Bacha, E. (1990) "O futuro do pacote", Folha de São Paulo, 22 de abril de 1990.

Bacha, E.; Cunha, L. R.; Franco, G.; Frisch, W. (1990) “Collor e o Congresso”, Jornal do Brasil, 29 de março de 1990, p. 11.

Barbosa, F. de H. “A inflação acabou?”, Folha de São Paulo, 10 de abril de 1990.

Belluzzo, L. G. (1990a) “O Choque de Zélia”, in Veja, 21 de março de 1990, p. 62

Belluzzo, L. G., \& Almeida, J. S. (1990b). Crise e reforma monetária no Brasil. São Paulo em Perspecti$v a, 4(1), 63-75$.

Braga, S. (1990) “Apoiar não significa aderir”, Jornal do Brasil, 21 de março de 1990.

Bresser-Pereira, L. C. (1990a), “As contradições do Plano”, Folha de São Paulo, 5 de abril de 1990.

Bresser-Pereira, L. C. (1990b), "Plano Collor: Apoiar e Ajustar", O Estado de São Paulo, 18 de março de 1990 , p. 54

Bresser-Pereira, L. C. (1990c) “A lógica do Plano”. Folha de São Paulo, 23 de março de 1990, p. A-3.

Bresser-Pereira, L. C. (1991) “As incertezas do Plano Collor”, Revista Brasileira de Economia 45(especial), janeiro 1991: 83-96.

Bresser-Pereira, L. C. (1996) “A inflação decifrada.” Revista de Economia Política, 6, no. 4 (1996): 64.

Bresser-Pereira, L. C., \& Nakano, Y. (1991). Hiperinflação e estabilização no Brasil: o primeiro Plano Collor. Revista de Economia Política, 11(4), 44.

Brígido, C. \& Alvarez, R. (2010) “Collor já pensava em confisco antes de eleito”. O Globo, 13 de março de 2010.

Cagan, P. (1956). The Monetary Dynamics of Hyperinflation in: Studies in the Quantity Theory of Money. Ed.Milton Friedman, University of Chicago Press, Chicago 1956.

Campos, R. de O. (1990), “A angústia dos liberais”, O Estado de São Paulo, 25 de março de 1990, p. 2.

Cardoso, E. (1990) “A grande depressão”, Folha de São Paulo, 20 de março de 1990

Carvalho, C. E. (1993) Liquidez dos haveres financeiros e zeragem automática do mercado. Revista de Economia Política, 13(1), 25-36.

Carvalho, C. E. (2000). O Plano Collor no debate econômico brasileiro. Pesquisa \& Debate. Revista do Programa de Estudos Pós-Graduados em Economia Política, 11 (1 (17).

Carvalho, C. E.. (2003). O fracasso do Plano Collor: erros de execução ou de concepção. EconomiA, Anpec, 4(2), 283-331.

Carvalho, C. E. (2006). As origens e a gênese do Plano Collor. Nova Economia, 16(1), 101-134.

Castro, L. B. de (2013). Privatização, Abertura e Desindexação: A Primeira Metade dos anos 90, in Giambiagi, F. et al.l (2011). Economia Brasileira Contemporânea [1945-2010]. Editora Elsevier,

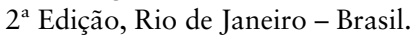

Collor de Mello, F. C. (1990) Discurso de posse in Jornal do Brasil de 17 de março de 1990, p. 1

Dall'Acqua, F. M. (1989). Imposto inflacionário: uma análise para a economia brasileira. Revista de Economia Política, 9(3).

Dornbusch, R. (1990) "Dornbusch prevê o fracasso do Plano de Zélia”, in Folha de São Paulo 14 de janeiro de 1990, p. A-10.

Folha de São Paulo (1990a) “Indefinição leva empresas a variar suas aplicações”, 18 de fevereiro de 1989 , p. 1

Folha de São Paulo (1990c), "Ex-diretor do BC diz que choque está correto e espera até deflação", 17 de março de 1990, p. B-11

Folha de São Paulo (1990d), "Professor da Unicamp acha plano incompleto", 17 de março de 1990, p. b-11.

Folha de São Paulo (1990e) “Economistas aprovam o plano do governo, mas fazem restrições”, 18 de março de 1990, p. b-14.

Folha de São Paulo (1990f) "Partido dará 'apoio integral' às medidas”, 19 de março de 1990, p. A-6. 
Folha de São Paulo (1990h) “Cúpula do PSDB elogia medidas econômicas”, 19 de março de 1990, p. A-6 Folha de São Paulo (1990i) "Apoio ao Plano cresce e chega a 81\%", 23 de março de 1990, p. a1 Galvêas, E. (1990a) "A grande concordata nacional”, Folha de São Paulo, 13 de abril de 1990, p. a2 Galvêas, E. (1990b) “O Plano de estabilização”, Folha de São Paulo, 25 de março de 1990.

Giambiagi, F., Zini, Jr. A. (1993). Renegociação da dívida interna mobiliária: uma proposta. Revista de Economia Política, São Paulo: Brasiliense, V, 13, 5-27.

Jornal do Brasil (1990a) (1990b) “Kafka diz due FMI gostou”, 18 de março de 1990, p.3.

Jornal do Brasil (1990c) "PT aplaude programa e apresenta sugestões”, 19 de março de 1990, p. 2

Jornal do Brasil (1990d) “Abílio acha que plano não é populista”, 19 de março de 1990, P. 7.

Jornal do Brasil (1990e) “Antônio Ermírio recomenda que se evitem demissões”, 21 de março de 1990, p. 13 Jornal do Brasil (1990f) “Conceição elogia plano na tv", 22 de março de 1990, p. 2.

Jornal do Brasil (1990g), "Mutirão para fechar medidas começou na terça”, 23 de março de 1990, p. 17. Jornal do Brasil (1990h) “Aceitação surpreende economistas”, 26 de março de 1990, p. 5

Jornal do Brasil (1990i), "Ex-presidentes do BC alertam para recessão”, 30 de março de 1990, p. 15 Jornal do Brasil (1990j) "Não basta só congelar a moeda", 14 de abril de 1990, p. 4.

Jornal do Brasil (19901) "Collor tem 67\% de aprovação e o plano econômico, 74\%", 25 de maio de 1990, P. 3.

Langoni, C. (1990) "A reforma econômica - riscos e vulnerabilidades”, Folha de São Paulo, 31 de março de 1990.

Leitão, M. (2013). Saga Brasileira. A Longa Luta de um Povo por sua Moeda, $8^{a}$ edição, Ed. Record, Rio de Janeiro - Brasil.

Maia, C. (1989a). Um acordo para a dívida interna. Folha de São Paulo, 2 de abril de 1989, p. B-2.

Maia, C. (1989b) “Quem perde com o Plano Collor”. Folha de São Paulo, 20 de março de 1990, p. A-3.

Mendonça de Barros, L. C. (1990) "A hora da verdade”, Folha de São Paulo, 1 de abril de 1990, p. B-9.

Nakano, Y. (1991) “As fragilidades do Plano Collor de estabilização.” Revista Brasileira de Economia, 45, pp. 136-156.

O Estado de São Paulo (1989a) “A reforma do Estado é a plataforma de todos”, 4 de agosto de 1989, p. 9.

O Estado de São Paulo (1990b), Economistas vêem riscos no programa, 22 de março de 1990, p. 43.

O Estado de São Paulo (1990c) “Os quatro atos do Plano Collor”, 23 de março de 1990.

O Estado de São Paulo (1990d) "Collor negocia pacote e sai fortalecido", 24 de março de 1990, p. 4.

O Estado de São Paulo (1990e) "PMDB revive fantasma da divisão", 15 de abril de 1990, p.4

Pastore, A. C. (1991). A reforma monetária do Plano Collor. Revista Brasileira de Economia, 45, 157-174.

Serra, J. (1990) “O Plano Cruzeiro”, Folha de São Paulo, 20 de março de 1990, p. A-2.

Setúbal, P. (1990) "O Plano Brasil Novo", in Folha de São Paulo 27 de março de 1990, p. B-2

Simonsen, M. H. (1990) "Controle da moeda é a chave de tudo", Jornal do Brasil, 18 de março de 1990, p.12

Simonsen, M. H. (1990) "O choque de Zélia” in Veja, 21 de março de 1990, p. 62

Simonsen, M. H. (1990) “Alea jact est”, Jornal do Brasil, 30 de março de 1990, p. 11.

Simonsen, Mario Henrique. “Aspectos técnicos do Plano Collor.” Revista Brasileira de Economia 45 (1991): 113-128.

Sonder, C. (1990) "Esperança com muita cautela", Jornal do Brasil, 29 de abril de 1990

Velloso, J. P. Dos Reis, (1990) "Plano Cruzeiro - primeira reação”, Folha de São Paulo, 24 de março de 1990.

Zini Jr, Á. (1990). O Brasil num cruzamento: dívida externa e exaustão fiscal. Revista de Economia Politica, 10(1), 32-52.

Zini Jr, Á. (1989a). Aprofundar o debate sobre dívida pública interna. Folha de S. Paulo, 6 de abril de 1989.

Zini Jr, Á. (1989b). Fundar a dívida pública do Brasil. Folha de S. Paulo, 18 de janeiro de 1989. 